\title{
Boron Doped Diamond Electrodes for Direct Measurement in Biological Fluids: An In Situ Regeneration Approach
}

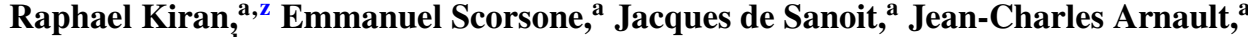 \\ Pascal Mailley, and Philippe Bergonzo ${ }^{\mathrm{a}}$
}

${ }^{a}$ CEA, LIST, Diamond Sensors Laboratory, 91191 Gif-sur-Yvette, France

${ }^{b}$ CEA- LITEN, Laboratoire de Stockage de l'Electricité, 73377 Le Bourget du Lac, France

\begin{abstract}
Boron doped diamond (BDD) electrodes are extremely promising in the field of biomedical applications as they exhibit a unique combination of properties. Despite these advantages, BDD electrodes are prone to fouling when used in biological fluids (urine, blood plasma), and synthetic fluids. We propose a electrochemical (EC) treatment where a train of short cathodic and/or anodic pulses are applied to clean fouled electrodes. This technique can be used to retrieve the lost reactivity, characterized by electron transfer rate $\mathrm{k}_{0}$ of the boron doped diamond electrodes, thereby enhancing their reusability over long period of measurements without degradation of the signal, thus significantly extending the field of monitoring and surveying applications. The technique does not require the use of a specific medium and thus can be directly performed in the probed fluid. Although an aqueous electrolyte containing non-electroactive species is preferred for EC activation, it can also be done in biological fluids such as blood, urine etc, thereby opening the field for in-vivo analysis. Through Electrochemical impedance spectroscopy (EIS) it was observed that the $\mathrm{k}_{0}$ value was increased up to $0.1 \mathrm{~cm} \mathrm{~s}^{-1}$ after the activation process. This technique improves the sensitivity, reproducibility and lifetime of the electrodes to a considerable extent.

(C) 2012 The Electrochemical Society. [DOI: 10.1149/2.014302jes] All rights reserved.
\end{abstract}

Manuscript submitted May 29, 2012; revised manuscript received October 22, 2012. Published November 14, 2012.

In biomedical and environmental applications, electrochemical sensors are well adapted due to their good sensitivity, fast measuring time, portability, low power consumption and cost effectiveness. BDD electrodes have been a major focus of research and development in electrochemical and biomedical sensors due to their electroanalytically advantageous features, ${ }^{1-6}$ namely: wide potential window in aqueous electrolytes $(>3 \mathrm{~V})$, corrosion stability in aggressive media, morphological and structural stability at very high current, low background current and bio-inertness. Despite these promising properties when compared to classical electrodes, they are also susceptible to fouling when used in organic or biological fluids. ${ }^{7-9}$ Electrode fouling can be due to adsorption or adhesion of biomolecules such as proteins, enzymes, cells, intermediate products of oxidation of organic compounds, etc. ${ }^{10-14}$ Hydrogen terminated BDD electrodes exhibit very good electrochemical reactivity characterized by the electron transfer rate $\mathrm{k}_{0} .{ }^{15}$ But aging in air or in aqueous solution reduces the $\mathrm{k}_{0}$ value to considerable extents, ${ }^{15,17}$ which could be due to surface modification. The $\mathrm{H}$ termination of as grown BDD electrode is gradually modified to $\mathrm{O}$ termination under exposure to air. Both fouling and aging affects the accuracy, sensitivity and reproducibility of the measurement and lifetime of the electrode. Moreover, as grown BDD electrodes grown in hot filament reactor contains adsorbed hydrocarbons and oxygen contamination and they affect the electrochemical properties of the electrode. ${ }^{16}$

Several approaches have been investigated to overcome this issue of fouling. For instance coating the electrochemical sensor with chemically inert polymers like Nafion enhances the antifouling capability. ${ }^{10,18}$ Surfactant modified electrode also enhances resistance to protein adsorption and cell adhesion. However, polymer or membrane deposition increases the degree of complexity of fabrication of the electrochemical sensor, decreases the electrode reactivity and as a result the lifetime of the modified electrode will be shorter than that of an 'as grown' electrode. Alternatively, sono-electrochemical method provides in-situ cleaning accompanied with electrochemical measurement. ${ }^{13}$ Nevertheless the power consumption, accuracy of measurement and simplicity of the design of the sensor have, in this case, to be compromised. Hydrogen plasma treatment is another approach that leads to clean $\mathrm{H}$ terminated BDD surface. ${ }^{19,20}$ But the use of plasma treatment is clearly not practical, especially when measurements have to be performed outside the laboratory. Electrochemical techniques have also been developed. In particular, an aged BDD electrode can be reactivated by cathodic pre-treatment by applying

${ }^{\mathrm{z} E-m a i l: ~ r a p h a e l . k i r a n @ c e a . f r ~}$
$-3 \mathrm{~V}$ for 3 to 30 minutes in $0.5 \mathrm{M} \mathrm{H}_{2} \mathrm{SO}_{4}$ aqueous solution. ${ }^{17}$ Also the non-diamond $\mathrm{sp}^{2}$ impurities can be eliminated by anodic treatment in aqueous electrolyte. ${ }^{19,21,22}$ Electrochemical reactivity of an aged electrode can be improved by performing 10 redox cycles in $0.5 \mathrm{M} \mathrm{LiClO}_{4}$ aqueous electrolyte (de-aerated) from $400 \mu \mathrm{A} \mathrm{cm}^{-2}$ to $-400 \mu \mathrm{A} \mathrm{cm}^{-2}$ at $100 \mathrm{mV} \mathrm{s}^{-1} .{ }^{15}$ Rodrigo et al. has demonstrated that anodic treatment of fouled electrode at $10 \mathrm{~mA} \mathrm{~cm}^{-2}$ for 30 minutes can recover initial reactivity of the electrode. ${ }^{30}$ This is due to oxidation of the organic molecule to $\mathrm{CO}_{2}$ by the electrogenerated hydroxyl radical $\left(\mathrm{OH}^{*}\right)$. On-line reactivation by anodic treatment ( $3 \mathrm{~V}$ for 30 minutes) was reported by some groups. ${ }^{31,32}$ However the analyte under investigation was of concentration range of milli molar and even micro molar range in a supporting electrolyte, when the on-line activation was done. Chloro-phenols and Carbamate compounds posses lower molecular weight compared to proteins and enzymes. Electrode fouling due to the phenolic derivatives is mainly due to the formation of passive polymeric formed as a result phenol oxidation. ${ }^{31}$ Human urine contains many proteins such as macroglobulin, fibrinogen, uromucoid, antegens of epithelial cells, etc. ${ }^{33}$ in addition to carbohydrates, hormones, fatty acids and other organic and inorganic compounds. Similarly blood contains many proteins like albumin, immunoglobulin, fibrinogen, enzymes, hormones and other high molecular weight species. The fouling of the electrode is not only due to deposition of polymeric film formed after oxidation of species, but also adsorption of these biomolecules. It was experimentally observed that a BDD electrode of high reactivity $\left(\mathrm{k}_{0}>0.1 \mathrm{~cm} \mathrm{~s}^{-1}\right)$ dropped its reactivity by an order of magnitude after being immersed in fetal bovine serum. Hence the anodic treatment technique demonstrated by other groups will not work in biological fluids. ${ }^{31,32}$ Furthermore anodic treatment results in reduced electron transfer rate, formation of passivation layer, shift in flatband potential etc. ${ }^{34}$

A pulsed cleaning technique has been reported by Mahé et al. ${ }^{35}$ where alternating current pulses of amplitude $\pm 250 \mathrm{~mA} \mathrm{~cm}^{-2}$ in $1 \mathrm{M}$ $\mathrm{HNO}_{3}$ were applied to clean the graphitic domains on diamond electrode and the total activation time is 400 seconds. We report herein an improved EC activation process for BDD electrodes, based on applying specific current or potential pulses, that lead to electrochemical cleaning and to remarkable electron transfer rates $\left(\mathrm{k}_{0}\right.$ value above $10^{-3} \mathrm{~cm} \mathrm{~s}^{-1}$ ) with good stability and an activation time shorter (as short as $400 \mathrm{~ms}$ when compared to longer activation time reported by other groups) than known prior art. ${ }^{28}$ This EC treatment does not require a specific electrolytic solution and has been successfully performed in a wide range of compounds, including biological fluids such as blood and urine. The in-situ cathodic treatment enhances the electron transfer rate when compared to anodic treatment due to $\mathrm{H}$ 
termination of surface. The surface modification of an EC activated electrode is explained from the analysis of X-ray Photoelectron Spectroscopy (XPS) results. Influence of current density, $\mathrm{pH}$, and number of pulses on EC activation is discussed. Some examples of activation within biological and synthetic fluids are also mentioned.

\section{Experimental}

BDD films of boron concentration near $2 \times 10^{21}$ at $\cdot \mathrm{cm}^{-3}$ were synthesized by microwave plasma enhanced chemical vapor deposition (MPECVD) using a metallic wall reactor over p-Si (100) substrate (Siltronix). ${ }^{23}$ The thickness of BDD layer was about $500 \mathrm{~nm}$ as measured by optical interferometry. The EC characterizations were carried out in a 3 electrode setup where BDD is the working electrode (working area $=0.5 \mathrm{~cm}^{2}$ ). Ultrapure deionised (DI) water (Millipore Direct Q3) was used to make all the solutions. Equimolar (1 mM) solutions of potassium ferricyanide(III)/ potassium hexacyanoferrate(II).trihydrate (Acros Organics) were prepared in $0.5 \mathrm{M}$ potassium chloride (Acros Organics) solution for EIS. 0.5 M lithium perchlorate (Sigma Aldrich) aqueous solution was prepared for EC activation of the electrodes. Activation of the electrodes was also performed using $0.2 \mathrm{M} \mathrm{Na}_{2} \mathrm{SO}_{4}, \mathrm{CuSO}_{4}, \mathrm{MnSO}_{4}, \mathrm{ZnSO}_{4}$ (Prolabo) aqueous solution, $0.2 \mathrm{M}$ tetrabutylammonium tetrafluoroborate (Sigma Aldrich) in acetonitrile, human urine (from healthy volunteer eating balanced diet), and bovine blood containing Ethylenediaminetetraacetic acid (freshly collected at the veterinary hospital Maison Alfort, France).

The electron transfer rate constant $\mathrm{k}_{0}\left(\mathrm{k}_{0}\right.$ is measured in $1 \mathrm{mM}$ ferro/ferricyanide in $0.5 \mathrm{M} \mathrm{KCl}$, through out the paper) was experimentally determined by EIS over a frequency range of $50 \mathrm{kHz}-1 \mathrm{~Hz}$ with logarithmic point spacing and potential amplitude of $0.01 \mathrm{~V} \mathrm{rms}$ while the BDD electrode was maintained at open circuit potential. The EIS was perfomed in a three electrode setup where BDD electrode is the working electrode, platinum wire the pseudo-reference electrode and platinum mesh the counter electrode. During cyclic voltammetry (CV) and EC treatment processes the pseudo reference was replaced by $\mathrm{Ag} / \mathrm{AgCl} / 3 \mathrm{M} \mathrm{KCl}$ electrode. The electrodes were rinsed in DI water and dried under flow of argon gas prior to each experiment.

The standard activation protocol is a pulse train of 50 current pulses of alternating amplitude $\left(10 \mathrm{~mA} \mathrm{~cm}^{-2}\right.$ and $\left.-10 \mathrm{~mA} \mathrm{~cm}^{-2}\right)$ and of equal duration $(100 \mathrm{~ms})$ applied between working and counter electrodes in $0.5 \mathrm{M} \mathrm{LiClO}_{4}$ solution. The parameters were varied according to the electrolytes. The standard cathodic activation protocol is a train of 50 current pulses of amplitude $-20 \mathrm{~mA} \mathrm{~cm} \mathrm{~cm}^{-2}$, duration of $110 \mathrm{~ms}$ and a duty cycle of $90.91 \%$. Autolab PGSTAT 302 potentiostat was used for all the EC characterizations. The $\mathrm{k}_{0}$ value was determined from the Nyquist plot fitted using ZSimWin 3.21 software. Unless stated otherwise the potential is always given versus an $\mathrm{Ag} / \mathrm{AgCl}$ reference electrode.

The quality of an electrode can be related to its electron transfer rate $\mathrm{k}_{0}$ which is defined by equation 1 and used to characterize our electrodes in the rest of the document. ${ }^{38}$

$$
\mathrm{k}_{0}=\left(\frac{\mathrm{RT}}{\mathrm{nF}}\right) \frac{1}{\mathrm{nSFR}_{\mathrm{T}} \mathrm{C}_{0}}
$$

Where $\mathrm{R}=$ Universal gas constant, $\mathrm{T}=$ Absolute temperature $(\mathrm{K})$, $\mathrm{S}=$ Surface area of the electrode $\left(\mathrm{cm}^{2}\right), \mathrm{F}=$ Faraday's constant $\left(96500 \mathrm{C} \mathrm{mol}^{-1}\right), \mathrm{R}_{\mathrm{T}}=$ Electron transfer resistance of electrode $(\mathrm{ohm})$, $\mathrm{C}_{0}=$ Concentration of redox couple $\left(\mathrm{mol} \mathrm{cm} \mathrm{cm}^{-3}\right), \mathrm{n}=$ number of electrons transferred. The higher the value of $\mathrm{k}_{0}$, the better is the reactivity of the electrode.

The surface analysis was performed using X-ray Photoelectron Spectroscopy (XPS). Two electrodes were treated under hydrogen plasma $\left(500^{\circ} \mathrm{C}\right)$ for 45 minutes. XPS analysis was carried on one sample directly after hydrogen plasma treatment whereas the other sample was activated prior to XPS analysis. The surface chemistry of the electrode was also characterized by XPS after fouling in urine. The spectrometer consists of a hemispherical analyzer and an $\mathrm{Al} \mathrm{K} \alpha$ anode supplied with a monochromator. Binding energies were referenced to the $\mathrm{Au} 4 \mathrm{f}_{7 / 2}$ peak located at $84 \mathrm{eV}^{29}$ According to the experimental

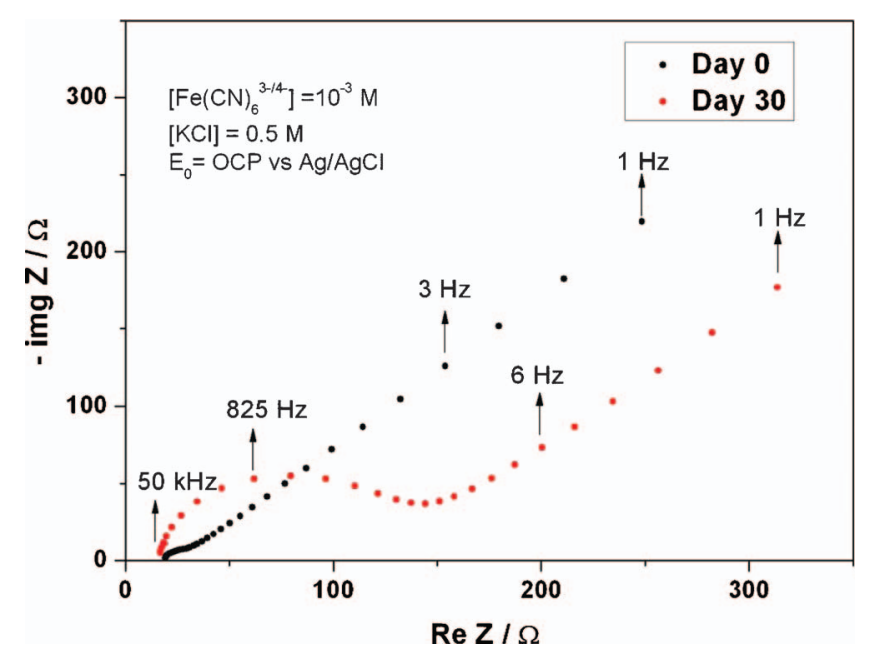

Figure 1. Comparison between the Nyquist plot of 'as grown' BDD electrode and that of the same electrode which has been exposed to air for 30 days.

geometry, the probed depth was estimated to be $1 \mathrm{~nm}$. A curve fitting procedure was carried out to extract the components in the $\mathrm{C} 1 \mathrm{~s}$ spectra using Voigt functions with a Lorentzian half-width of $0.2 \mathrm{eV}$. The Gaussian width was considered as an adjustable parameter. Then the area of each peak was calculated and the ratio of this area was recorded with respect to the total area.

\section{Results}

Activation of aged and fouled electrodes. - 'As grown' BDD electrodes exhibit very high reactivity with $\mathrm{k}_{0}$ values above $0.01 \mathrm{~cm} \mathrm{~s}^{-1}$. The peak to peak separation of the oxidation and reduction potential $\left(\triangle \mathrm{E}_{\mathrm{p}}\right.$ in $\left[\mathrm{Fe}(\mathrm{CN})_{6}\right]^{3-14-}$ solution) of such an electrode was probed at $60 \mathrm{mV}$ at a $100 \mathrm{mV} \mathrm{s}^{-1}$ scan rate, a value close to the theory for this couple, and demonstrating the extreme reactivity of the diamond surface. The $\mathrm{k}_{0}$ value for this electrode was probed at $5.9 \times 10^{-2} \mathrm{~cm} \mathrm{~s}^{-1}$. However, when exposed to air for 30 days (in laboratory condition), the same electrode demonstrated a decrease of the $\mathrm{k}_{0}$ value by $1100 \%$. The transfer resistance $\mathrm{R}_{\mathrm{T}}$ was increased from 10 to $105 \Omega$ and $\Delta \mathrm{E}_{\mathrm{p}}$ value decreased by $42 \%$.

We used our very innovative EC treatment on the aged electrode in $\mathrm{LiClO}_{4}$ solution by applying a train of alternating square wave current pulses on the working electrode with respect to the counter electrode. The standard activation protocol was used to activate the electrode. It was observed that the electrode activity was recovered, with probed $\Delta \mathrm{E}_{\mathrm{p}}$ value brought back to $60 \mathrm{mV}$ and $\mathrm{k}_{0}$ value reaching $6.1 \times 10^{-2} \mathrm{~cm} \mathrm{~s}^{-1}$ after this novel EC treatment. Figure 1 shows Nyquist plots of an aged electrode and the electrode after electrochemical activation. The time required to bring back the lost reactivity of the aged electrode, in this case, was kept low at a value of 10 seconds. With respect to other techniques ${ }^{13,15,19-22}$ as previously reported in the literature, this technique is much faster, can be performed using an extremely simple electronic setup (pulse generator), and requires lower power resources.

A set of $5 \mathrm{CV}$ cycles from $-0.4 \mathrm{~V}$ to $1.1 \mathrm{~V}$ vs $\mathrm{Ag} / \mathrm{AgCl}$ at 100 $\mathrm{mV} \mathrm{s}^{-1}$ was performed in human urine using a freshly prepared BDD electrode and after each trial EIS was done to assess the $\mathrm{k}_{0}$ value. An oxidation peak (P1) was observed at approximately $0.5 \mathrm{~V}$ vs $\mathrm{Ag} / \mathrm{AgCl}$ (Figure 2a). The peak (P1) corresponds to the oxidation potential of uric acid and ascorbic acid in urine. ${ }^{25}$ However the amplitude of P1 is observed to significantly decrease after each trial. Also the oxidation potential of this peak shifts toward more positive potentials and the $\mathrm{k}_{0}$ value decreases after each trial (Figure $2 \mathrm{a}$ ). The attenuation of current is not because of diffusion limited phenomena the electrode was washed thoroughly in DI water and dried before each scan. Before the measurement, a $\mathrm{k}_{0}$ value of $0.27 \mathrm{~cm} \mathrm{~s}^{-1}$ was observed, whereas 


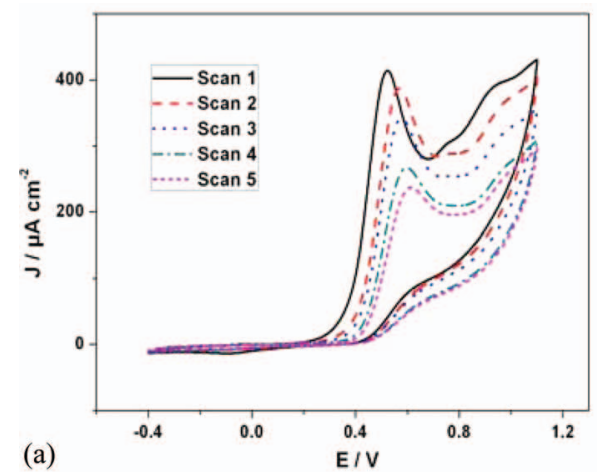

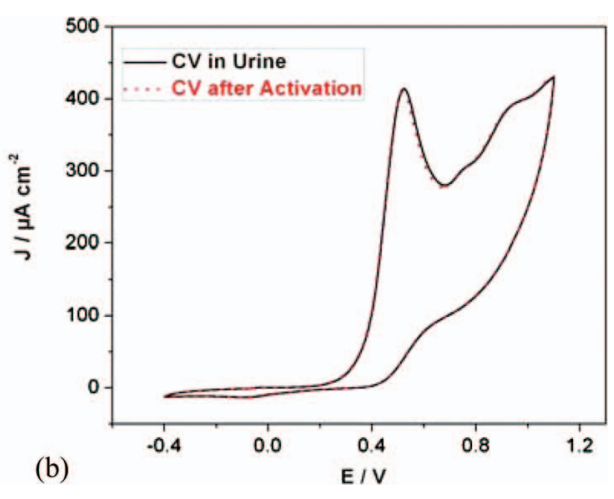

Figure 2. (a) Cyclic voltammogram in human urine from $-0.4 \mathrm{~V}$ to $1.1 \mathrm{~V}$ at $100 \mathrm{mV} \mathrm{s}^{-1}$ where $\mathrm{J}$ is the current density in $\mu \mathrm{A} \mathrm{cm} \mathrm{cm}^{-2}$ and $\mathrm{E}$ is the applied voltage in volts. The electrode was cleaned thoroughly in deionized water prior to each scan and hence the attenuation of the peak (P1) is due to fouling and not because the solution surrounding electrode is depleted of electro-active species. (b) Comparison of the cyclic voltammogram of 'as grown' electrode (solid line) and the same electrode after activation (dotted line) where $J$ is the current density in $\mu \mathrm{A} \mathrm{cm}^{-2}$ and $\mathrm{E}$ is the applied voltage in volts. The electrolyte is human urine and the scan rate is $100 \mathrm{mVs}^{-1}$. after five trials it decreased to values lower than $10^{-3} \mathrm{~cm} \mathrm{~s}^{-1}$. This clearly corresponds to the fouling of the electrode. ${ }^{26}$ However, this fouled electrode was treated by our EC activation technique using the following parameters. A set of 150 current pulses of alternating amplitudes $\left(10 \mathrm{~mA} \mathrm{~cm}^{-2}\right.$ and $\left.-10 \mathrm{~mA} \mathrm{~cm}^{-2}\right)$ and of equal duration $(100 \mathrm{~ms})$ was applied to the working electrode with respect to the counter electrode in $\mathrm{LiClO}_{4}$ solution. The total number of pulses were tripled when compared to standard activation protocol because it was observed that the $\mathrm{k}_{0}$ value after 50 pulses was not as high as that of as grown electrode (although significantly higher than $0.01 \mathrm{~cm} \mathrm{~s}^{-1}$ ). This corresponds to an overall activation time of 30 seconds. The results were extremely convincing as it can be observed in Figure $2 \mathrm{~b}$ that the $\mathrm{CV}$ curve after activation perfectly coincides with that of the first scan. The difference in amplitude of the P1 peak for these two curves remained below $0.0001 \%$ and the $\mathrm{k}_{0}$ value was brought back to more than $0.2 \mathrm{~cm} \mathrm{~s}^{-1}$ by this activation.

Activation in other electrolytes. - This EC activation approach can also successfully be performed in most inorganic salt solutions as well as organic solutions. In order to demonstrate this, electrodes were fouled and then activated in various electrolytes. For examples, the BDD electrodes were fouled in red wine (Chassagne-Montrachet $1^{\text {er }} \mathrm{Cru}$ ) by maintaining them at $0.7 \mathrm{~V}$ vs $\mathrm{Ag} / \mathrm{AgCl}$ for $20 \mathrm{~s}$. The red wine sample was particularly chosen since it led to high level electrode fouling. ${ }^{27}$ The fouled electrodes were exhibiting $\mathrm{k}_{0}$ values below $10^{-3} \mathrm{~cm} \mathrm{~s}^{-1}$. Electrodes were then activated in different salt solution using 8 alternating current pulse $\left(+1.5 \mathrm{~mA} \mathrm{~cm}^{-2}\right.$ and $\left.-1.5 \mathrm{~mA} \mathrm{~cm}^{-2}\right)$ of 2 seconds each. The $\mathrm{k}_{0}$ value, after activation in each salt solution, is summarized in Table I. This demonstrated the role of cathodic current pulses in electrode cleaning. For non-electroactive electrolytes such as $\mathrm{LiClO}_{4}$ and $\mathrm{Na}_{2} \mathrm{SO}_{4}$ at this current density, the negative potential goes beyond $-1.6 \mathrm{~V}$ where $\mathrm{H}_{2}$ gas is electro-generated. The electrogenerated $\mathrm{H}_{2}$ gas helps in desorption of adsorbed organic species and $\mathrm{H}$ termination of the electrode. Whereas for the electroactive electrolyte the current generated was mainly due to metal deposition rather than $\mathrm{H}_{2}$ electro-generation and hence the $\mathrm{k}_{0}$ value is lower. At a relatively low current density of $1.5 \mathrm{~mA} \mathrm{~cm}^{-2}$, electroactive species such as $\mathrm{Cu}, \mathrm{Zn}$ and $\mathrm{Mn}$ salts gets electrodeposited on the surface and thereby decreasing the yield of $\mathrm{OH}^{*}$, which plays a critical role in electrode cleaning. The deposition of metals were observed by the

$\begin{aligned} & \text { Table I. The electron transfer rate }\left(\mathbf{k}_{0}\right) \text { value determined from the } \\ & \text { Nyquist plot after activation in salt solutions. }\end{aligned}$
$\begin{array}{lcc}\text { Salt } & \text { Solvent } & k_{0}\left(\mathrm{~cm} \mathrm{~s}^{-1}\right) \\ \mathrm{LiClO}_{4} & \text { Water } & 0.0268 \pm 8 \mathrm{e}-4 \\ \mathrm{Na}_{2} \mathrm{SO}_{4} & \text { Water } & 0.0205 \pm 6 \mathrm{e}-4 \\ \mathrm{MnSO}_{4} & \text { Water } & 0.0108 \pm 0.004 \\ \mathrm{ZnSO}_{4} & \text { Water } & 0.0027 \pm 7 \mathrm{e}-4 \\ \mathrm{CuSO}_{4} & \text { Water } & 0.0013 \pm 6 \mathrm{e}-4 \\ \mathrm{H}_{2} \mathrm{SO}_{4} & \text { Water } & 0.0197 \pm 3 \mathrm{e}-3 \\ \mathrm{TBATFB} & \text { Acetonitrile } & 0.0095 \pm 4 \mathrm{e}-4\end{array}$

anodic stripping voltammogram where $\mathrm{Zn}$ was stripped at $-0.9 \mathrm{~V}$, $\mathrm{Cu}$ at $0.4 \mathrm{~V}$ and for $\mathrm{Mn} 2$ peaks were observed (oxidation and reduction peak). It was observed that at higher current density $(>10 \mathrm{~mA}$ $\mathrm{cm}^{-2}$, the $\mathrm{k}_{0}$ value was higher after activation in some electro-active electrolyte) because the yield of $\mathrm{H}_{2}$ generation and $\mathrm{H}$ termination increases with current density. Activation process in 0.2 M TBATFB in acetonitrile solution demonstrated that activation process can also be successfully performed in organic solvents to reach considerably high $\mathrm{k}_{0}$ values above $10^{-3} \mathrm{~cm} \mathrm{~s}^{-1}$.

Influence of $p H$, current density and number of pulses on EC activation.- To probe the influence of factors such as the amplitude of the current density, the $\mathrm{pH}$ of the electrolytic solution and the number of pulses in a pulse train, we varied one of such parameter at a time while the two others were kept constant. To measure the influence of $\mathrm{pH}$ and number of pulses, the total activation duration was fixed at 16 seconds. But for current density, the duration of activation was limited to $100 \mathrm{~ms}$ because the current density was varied from $1 \mu \mathrm{A}$ to $100 \mathrm{~mA} \mathrm{~cm}^{-2} .16$ seconds of activation at $100 \mathrm{~mA} \mathrm{~cm}^{-2}$ electrolyze the solution rapidly and may also affect the surface termination although BDD is known to be robust.

At first, the electrodes were fouled in the red wine to reach $\mathrm{k}_{0}$ values below $10^{-3} \mathrm{~cm} \mathrm{~s}^{-1}$ and then activated in $0.5 \mathrm{M} \mathrm{LiClO}_{4}$ solutions with varying $\mathrm{pH}$ values. The $\mathrm{pH}$ was adjusted to $1.5,4.5,7,9.5$ and 12.5 by adding either $\mathrm{H}_{2} \mathrm{SO}_{4}$ or $\mathrm{NaOH}$. Activation was performed using 8 current pulses of alternating amplitude $\left(1.5 \mathrm{~mA} \mathrm{~cm} \mathrm{~cm}^{-2}\right.$ and $-1.5 \mathrm{~mA} \mathrm{~cm}^{-2}$ ) and duration of 2 seconds each. The more alkaline the solution, better the activation of the electrode as displayed in Figure 3 . The $\mathrm{k}_{0}$ value of the electrode after activation in a solution

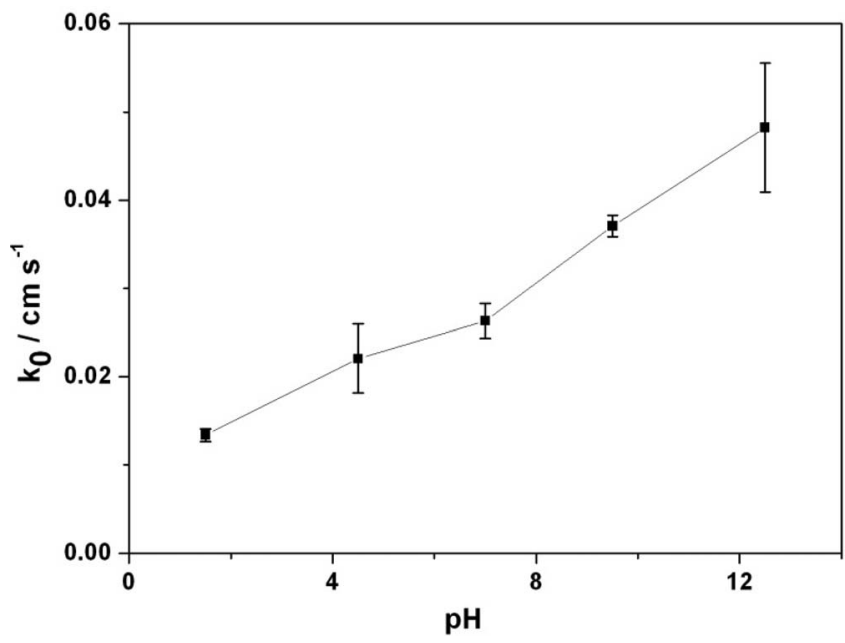

Figure 3. $\mathrm{pH}$ dependence of activation process. The higher the $\mathrm{pH}$, the better the activation and the value of electron transfer rate (measured in $1 \mathrm{mM}$ ferro/ferricyanide in $0.5 \mathrm{M} \mathrm{KCl}$ ) $\mathrm{k}_{0}$ measured in $\mathrm{cm} \mathrm{s}^{-1}$. 


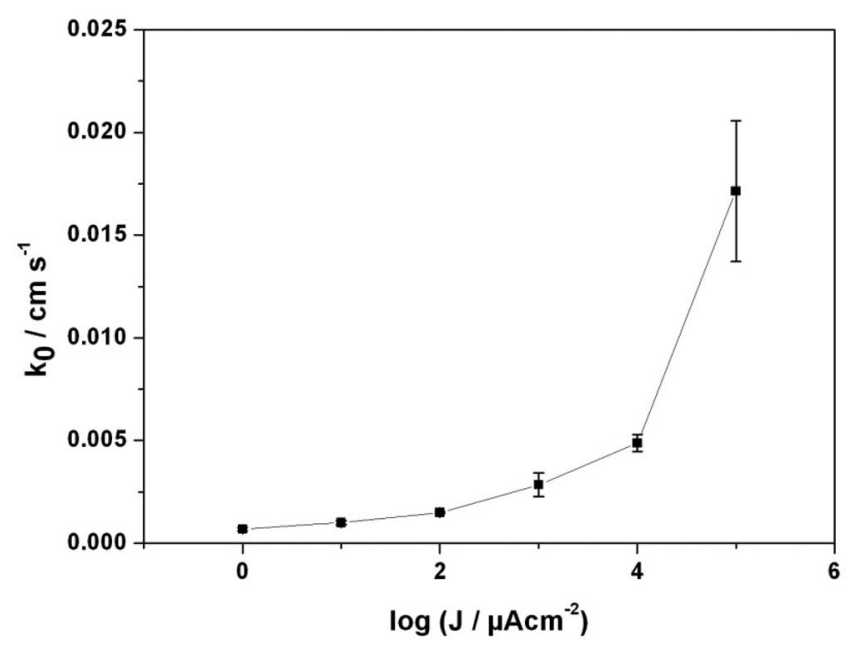

Figure 4. Effect of the current density on the activation process. The higher the current density, the higher the electron transfer rate $\mathrm{k}_{0}\left(\mathrm{~cm} \mathrm{~s}^{-1}\right)$, where $\mathrm{J}$ is the current density in $\mu \mathrm{A} \mathrm{cm}^{-2}$.

of $\mathrm{pH} 1.5$ was found to be $1.34 \times 10^{-2} \mathrm{~cm} \mathrm{~s}^{-1}$ whereas that of an electrode activated in alkaline solution of $\mathrm{pH} 12.5$ was $4.82 \times 10^{-2}$ $\mathrm{cm} \mathrm{s}^{-1}$. We, thus, observe an increase of around $250 \%$ in $\mathrm{k}_{0}$ when the fouled electrode is activated in an alkaline medium as compared to that in an acidic medium. This could possibly be associated to the fact that, when alternating positive and negative pulses were applied through the working electrode, $\mathrm{OH}^{*}$ radicals generated may play a relevant role to oxidize organic compounds. ${ }^{1,24}$ Electrode fouling is associated with the deposition or adsorption of organic compounds on the electrode surface and the $\mathrm{OH}^{*}$ radicals play an important role in oxidizing them to $\mathrm{CO}_{2}$. Alkaline solution produce more $\mathrm{OH}^{*}$ radicals when compared to acidic solutions.

Increasing the current density of the current pulses causes a very dramatic increase in $\mathrm{k}_{0}$ value (Figure 3 ). The electrodes were fouled in red wine and then were activated in $0.5 \mathrm{M} \mathrm{LiClO}_{4}$ solution using 4 alternating current pulses of $100 \mathrm{~ms}$ duration each, while the $\mathrm{pH}$ of the solution was kept constant $(\mathrm{pH}=4.5)$. This activation was performed using varying current density amplitudes of $1 \mu \mathrm{A} \mathrm{cm}^{-2}$, $10 \mu \mathrm{A} \mathrm{cm} \mathrm{cm}^{-2}, 100 \mu \mathrm{A} \mathrm{cm} \mathrm{cm}^{-2}, 1 \mathrm{~mA} \mathrm{~cm} \mathrm{~cm}^{-2}, 10 \mathrm{~mA} \mathrm{~cm}$ and $100 \mathrm{~mA} \mathrm{~cm}{ }^{-2}$, respectively. The $\mathrm{k}_{0}$ of the electrode after activation using a current density of $1 \mu \mathrm{A} \mathrm{cm}^{-2}$ was $6.97 \pm 0.8 \times 10^{-4} \mathrm{~cm} \mathrm{~s}^{-1}$ and that of an electrode activated using a current density of $100 \mathrm{~mA}$ $\mathrm{cm}^{-2}$ was $1.71 \pm 0.3 \times 10^{-2} \mathrm{~cm} \mathrm{~s}^{-1}$. Maintaining constant the total time of activation and $\mathrm{pH}$, the result is an increase of the $\mathrm{k}_{0}$ value by up to a factor 25 with the current density.

The number of pulses required to activate the electrode also plays a very critical role. This was assessed by varying the total number of pulses per activation, whereas the total activation time, $\mathrm{pH}$ and current density were kept constant $(\mathrm{pH}=4.5)$. Alternating current pulses of absolute amplitude of $1.5 \mathrm{~mA} \mathrm{~cm}^{-2}$ were applied through the fouled electrode in $0.5 \mathrm{M} \mathrm{LiClO}_{4}$ solution and the total activation time was 16 seconds. The fouled electrode was activated using series of 2,4 , $8,16,32$ and 64 alternating pulses and with the corresponding pulses exhibiting durations of $8,4,2,1,0.5$ and 0.25 seconds, respectively. It was observed that the more the number of pulses for a finite activation time, the better the yield of activation. When 2 alternating pulses of 8 seconds each were applied, the post activation $\mathrm{k}_{0}$ was $8.2 \pm 0.7$ $\times 10^{-3} \mathrm{~cm} \mathrm{~s}^{-1}$, and values reached $2.1 \pm 0.1 \times 10^{-2} \mathrm{~cm} \mathrm{~s}^{-1}$ when 64 alternating pulses were applied (Figure 5). A $250 \%$ increase was observed for the $\mathrm{k}_{0}$ value when the number of pulses was increased from 2 to 64 for an activation time period of 16 seconds. This demonstrates the reason for using several pulses instead of just 2 pulses (Cathodic and anodic).

From Figure 5 it is clear that there is a enormous increase in $\mathrm{k}_{0}$ value when the number of pulses were increased from 1 to 10 and the

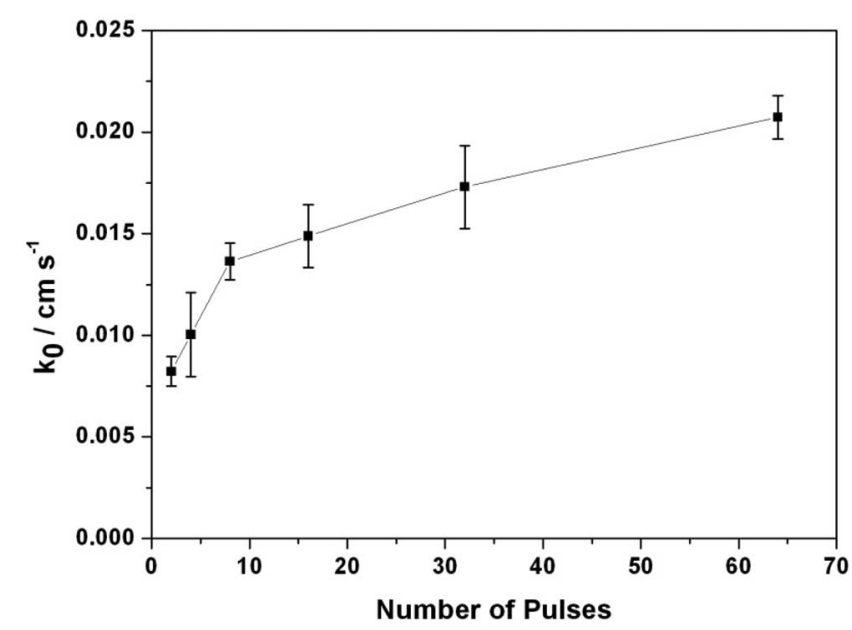

Figure 5. Impact of the number of pulses on the activation process, where $\mathrm{k}_{0}$ is electron transfer rate $\left(\mathrm{cm} \mathrm{s}^{-1}\right)$.

slope is relatively gradual when the number of pulses were increased further. Similarly there is a enormous increase in $\mathrm{k}_{0}$ value when the current density was increased beyond $10 \mathrm{~mA} \mathrm{~cm}^{-2}$ as seen in Figure 4 . Based on these assumptions and experimental findings the standard activation protocol is suggested to clean the electrode in a non-reactive aqueous electrolyte: Positive and negative trains of pulses of the same amplitude $\left( \pm 10 \mathrm{~mA} \mathrm{~cm}^{-2}\right)$ and duration $(100 \mathrm{~ms}$ each $)$ and series of 100 such pulses.

Surface analysis and activation mechanism. - The surface modifications induced by the activation treatment were characterized using X-ray Photoemission Spectroscopy (XPS) using a surface sensitive geometry. After hydrogen plasma, no oxygen was detected using XPS corresponding to values below the detection threshold of 0.5 at $\%$. In addition to the $\mathrm{C}-\mathrm{C} \mathrm{sp}{ }^{3}$ / C-H major peak located at $283.9 \mathrm{eV}$, the $\mathrm{C} 1 \mathrm{~s}$ signal exhibits a shoulder at $+0.6 \mathrm{eV}$ corresponding to $\mathrm{CH}_{\mathrm{x}}(\mathrm{x}>1)$ bonds which represents $19 \%$ of the $\mathrm{C} 1$ s total area (Table II). This signature was previously reported for hydrogenated diamond surfaces. ${ }^{15}$ Finally, a negligible contribution $(<0.5$ at $\%)$ was detected at $282.5 \mathrm{eV}$ corresponding to $\mathrm{sp}^{2}$ carbon. This is related to the grain size of nanocrystalline boron doped diamond films leading to a weak contribution from grain boundaries. After fouling in urine, oxygen and nitrogen are measured at the electrode surface with concentrations of 17.6 at $\%$ and 7.9 at $\%$, respectively. This leads to a broadening of the $\mathrm{C} 1 \mathrm{~s}$ peak (FWHM $1.8 \mathrm{eV}$ compared to $0.8 \mathrm{eV}$ after hydrogenation). After activation, the oxygen concentration extracted from the $\mathrm{O} 1 \mathrm{~s}$ core level was of 3.8 at\%. Two new contributions have to be taken into account at the $\mathrm{C} 1 \mathrm{~s}$ core level. The first one is located at $+1.3 \mathrm{eV}$ from the $\mathrm{C}-\mathrm{C} \mathrm{sp} 3$ / C-H peak and could be assigned to $\mathrm{C}-\mathrm{OH}$ bonds. The second weaker contribution at $1.9 \mathrm{eV}$ from the $\mathrm{C}-\mathrm{C} \mathrm{sp} \mathrm{sp}^{3}$ is attributed to $\mathrm{C}-\mathrm{O}-\mathrm{C}$ bonds (Table II). This surface chemistry is close to the one measured after activation in $\mathrm{LiClO}_{4}$ electrolyte ${ }^{15}$ where $\mathrm{C}-\mathrm{OH}(4 \%)$ and $\mathrm{C}-\mathrm{O}-\mathrm{C}(5 \%)$ contributions were also present.

During EC activation, three mechanisms are expected to occur: (i) oxidation of adsorbed organic molecule by $\mathrm{OH}^{*}$, (ii) $\mathrm{H}$ termination during cathodic pulsing, ${ }^{36}$ (iii) desorption of adsorbed organic compounds by electro-generated gaseous species. It was experimentally observed that the activation in basic solution has yielded better

Table II. Percentages of total C1s area of the XPS components for hydrogenated electrode and electrode after EC activation.

\begin{tabular}{|c|c|c|c|c|c|}
\hline & $\mathrm{C}-\mathrm{C} \mathrm{sp}{ }^{2}$ & $\mathrm{C}-\mathrm{C} \mathrm{sp}^{3} / \mathrm{C}-\mathrm{H}$ & $\mathrm{CH}_{\mathrm{x}}$ & $\mathrm{C}-\mathrm{OH}$ & $\mathrm{C}-\mathrm{O}-\mathrm{C}$ \\
\hline & & $81^{c}$ & $19 \%$ & & \\
\hline Pulse activated BDD & $<0.5 \%$ & $72 \%$ & $20 \%$ & $6 \%$ & \\
\hline
\end{tabular}




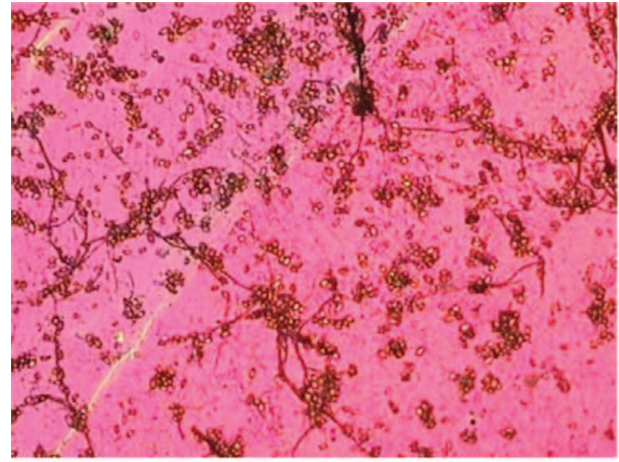

(a)

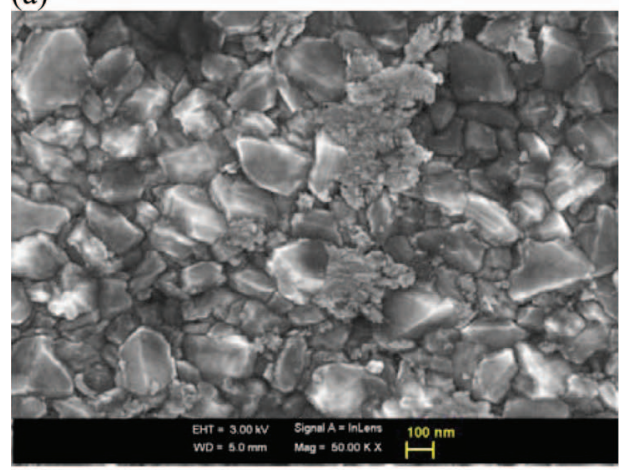

(c)

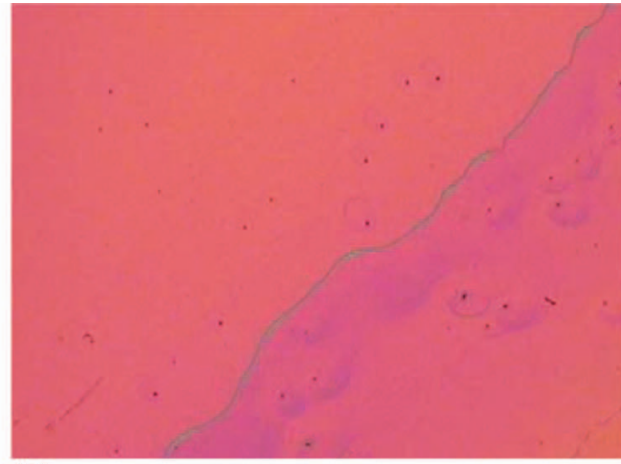

(b)

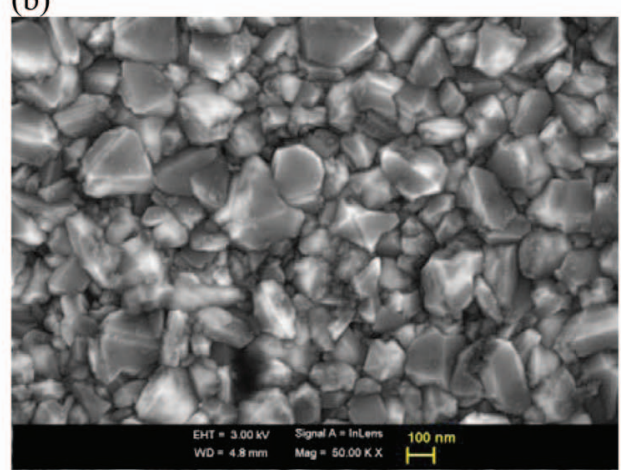

(d)

Figure 6. Optical microscopic (10× magnification) and SEM images of electrode deposited with biofilm (a,c) and after 3 standard activation protocol (b,d).

reactivity when compared to acidic solutions. $\mathrm{OH}^{*}$ formation is explained by the following chemical equation: ${ }^{37}$

$$
\mathrm{H}_{2} \mathrm{O} \rightarrow \mathrm{OH} *+\mathrm{H}^{+}+\mathrm{e}^{-}
$$

$\mathrm{OH}^{*}$ generated are oxidants and they oxidize the adsorbed organic molecule to $\mathrm{CO}_{2}$.

$$
\mathrm{OH} *+\mathrm{R} \rightarrow \mathrm{mCO}_{2}+\mathrm{nH}_{2} \mathrm{O}+\mathrm{e}^{-}
$$

The concentration of $\mathrm{OH}^{*}$ increases progressively until a constant value is reached due to mass transfer limitations or chemical destruction of the $\mathrm{OH}^{*}$ formed. At higher $\mathrm{pH}$ more $\mathrm{OH}^{*}$ is generated. $\mathrm{LiClO}_{4}$ is non-electroactive species and hence the only oxidant species is $\mathrm{OH}^{*}$.

The double layer capacitance of the electrode was measured before and after activation. Two techniques were used for measurement of capacitance: $\mathrm{CV}$ (The electrode was scanned in $0.5 \mathrm{M} \mathrm{LiClO}_{4}$ solution at $100 \mathrm{mV} \mathrm{s}^{-1}$ ) and charge-discharge curves (I-t plot, where the electrode was held at $0 \mathrm{~V}$ for $0.005 \mathrm{~s}$ and $0.05 \mathrm{~V}$ for $0.005 \mathrm{~s}$ ). There was no significant difference in the capacitance value (less than $0.5 \%$ ) before and after activation. XPS analysis, high $\mathrm{k}_{0}$ value and negligible change in double layer capacitance indicate that there is no significant difference between as grown electrode and EC activated electrode in terms of electrochemical reactivity and surface termination.

BDD electrodes were horizontally immersed in an aquarium containing fish and aquatic plants for 90 days. The electrodes were then rinsed in DI water, dried and were observed under optical microscope. A biofilm was formed on the surface which consists of several microbial communities. SEM and optical microscopic images (Figure 6) shows that the BDD surface was masked by the microbes. EC characterization such as EIS and CV were performed between varies steps of EC activation. It took 3 standard activation protocol to clean the electrode completely and get a $\Delta \mathrm{E}_{\mathrm{p}}$ (in $\left[\mathrm{Fe}(\mathrm{CN})_{6}\right]^{3-/ 4-}$ solution) of $60 \mathrm{mV}$ and $\mathrm{a} \mathrm{k}_{0}>0.1 \mathrm{~cm} \mathrm{~s}^{-1}$. It was observed from SEM and optical images that the microbes have been completely removed by 3 steps of standard activation protocol. 3 processes outline the activation process: $\mathrm{OH}^{*}$ might have destroyed the microbes, electro-generated $\mathrm{O}_{2}$ and $\mathrm{H}_{2}$ gas bubbles helped in desorbing the attached microbes and cathodic pulse have $\mathrm{H}$ terminated the surface.

$4 \mathrm{H}$ terminated BDD samples were prepared: sample 1 is an 'as grown' BDD electrode, sample 2,3 and 4 are electrodes fouled by $5 \mathrm{CV}$ scans in human urine. Sample 3 and 4 were cleaned using standard cathodic protocol in urine and standard activation protocol respectively. The fouled sample (2) was very cloudy under SEM (Figure 7) and the underlying BDD film was not clearly observed suggesting a nonconductive biomolecule (enzyme, protein, fat etc.) layer over BDD film. It was observed that the samples 1 and 4 resembles nearly the same suggesting that the sample 4 has been almost cleaned with the help of $\mathrm{OH}^{*}$ generated that has oxidized the adsorbed biomolecules, desorption of the adsorbed species by electrogenerated $\mathrm{H}_{2}$ and $\mathrm{O}_{2}$ bubbles and cathodic pulse $\mathrm{H}$ terminating (observed by high $\mathrm{k}_{0}$ values). Sample 3 was almost cleaned with less cloudy appearances. There was no generation of $\mathrm{OH}^{*}$ as the activation was cathodic. Hence the cleaning was due to desorption of the adsorbed species by electro-generated $\mathrm{H}_{2}$ bubbles and $\mathrm{H}$ termination of surface (observed by high $\mathrm{k}_{0}$ values).

In-situ activation in biological fluids. - A set of 9 trials each comprising of $3 \mathrm{CV}$ scans were performed in human urine and the current density of the $1^{\text {st }}$ peak (P1) of the first scan were recorded. The electrode was then activated in urine for all the trials except before trial no: 4, 7, and 9. The EIS of the electrode was then recorded to enable the comparison of the $\mathrm{k}_{0}$ values between activated and nontreated trials. Activation in human urine was performed using a train of negative current pulses of 50 pulses. Each pulse has amplitude of $-20 \mathrm{~mA} \mathrm{~cm} \mathrm{~cm}^{-2}$, duration of $110 \mathrm{~ms}$ and a duty cycle of $90.91 \%$. It was observed that the mean value of $\mathrm{k}_{0}$ for an activated electrode was around $0.01 \mathrm{~cm} \mathrm{~s}^{-1}$. When the electrode was not activated this value was reduced by a factor of 40 with respect to an activated electrode. From Figure 8 it clearly appears that once the electrode is activated after a non-treated trail, one can bring back the lost reactivity of the electrode as well as a $\mathrm{k}_{0}$ value close to mean values. Similarly the mean current density $\mathrm{J} 1$ of the peak P1 for the activated trials was 


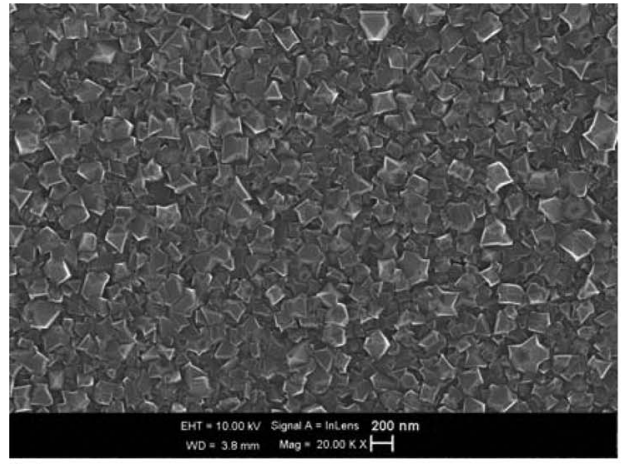

(a)

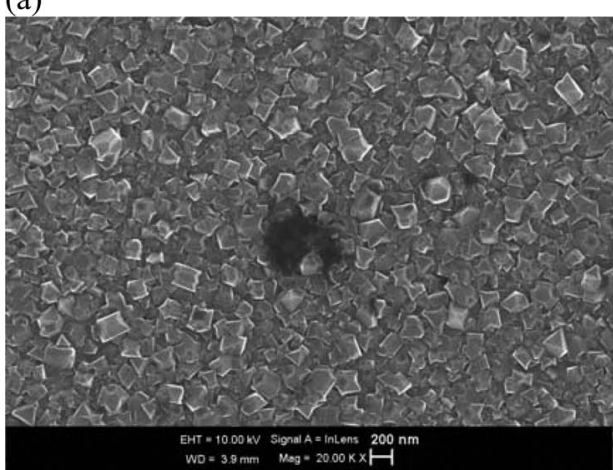

(c)

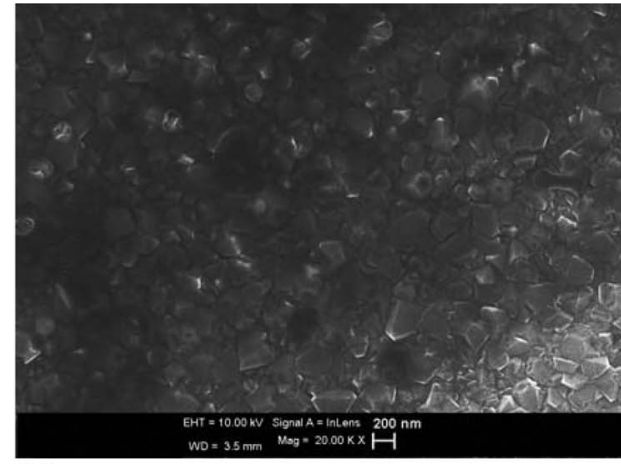

(b)

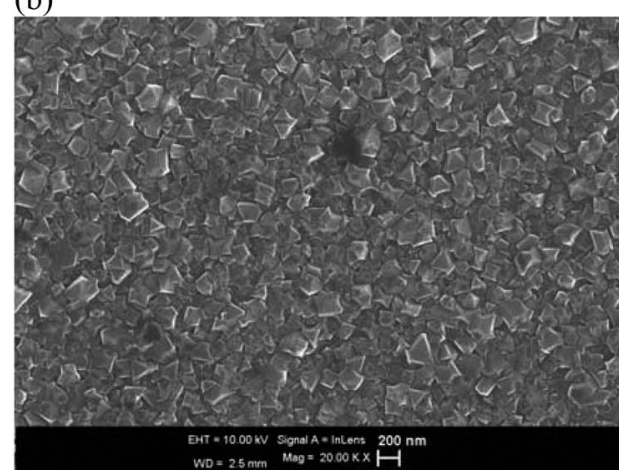

(d)

Figure 7. SEM images of as grown electrode (a), electrode after being fouling in urine (b) after activation in urine (c) and after activation in $\mathrm{LiClO}_{4}(\mathrm{~d})$.

observed to be $345 \mu \mathrm{A} \mathrm{cm}^{-2}$. For the non- treated trials this value was only $3 / 4^{\text {th }}$ of the activated trials. This value was brought back to mean values by activation in urine as seen in Figure 9.

Another illustration used a BDD electrode of high reactivity $\left(\mathrm{k}_{0}\right.$ $=0.1 \mathrm{~cm} \mathrm{~s}^{-1}$ ) dipped in bovine blood for two hours. This results in a drop of $\mathrm{k}_{0}$ to $0.007 \mathrm{~cm} \mathrm{~s}^{-1}$. The EC activation was then performed directly in bovine blood by applying a train of negative current pulses consisting of 50 pulses where each pulse exhibits an amplitude of $-20 \mathrm{~mA} \mathrm{~cm}{ }^{-2}$, a duration of $110 \mathrm{~ms}$ and a duty cycle of $90.91 \%$

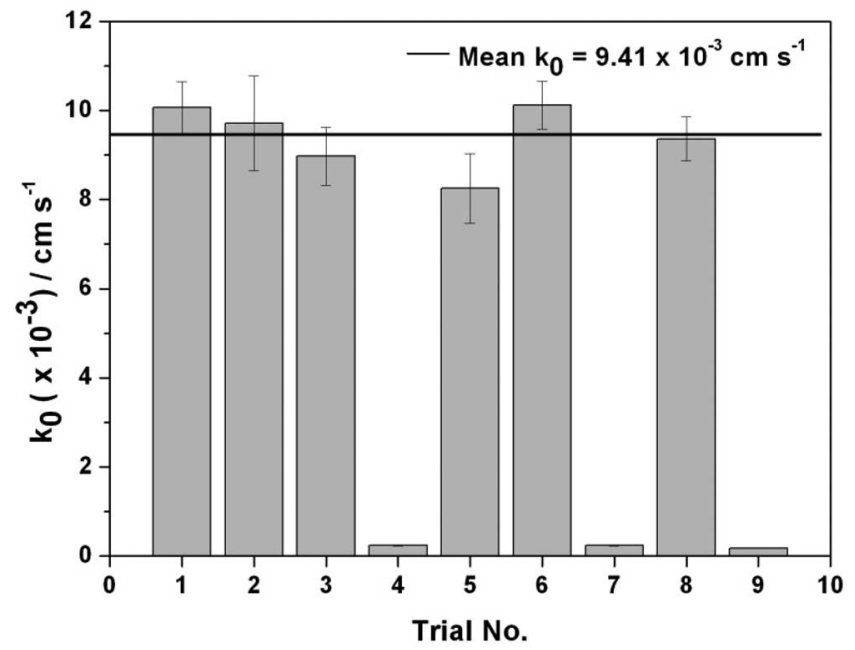

Figure 8. Electron transfer rate $\mathrm{k}_{0}$ is measured after each trial. For trial no: 4, 7 and 9, the electrode was not activated in urine. For all other trials, the electrode was activated in urine and as a result the $\mathrm{k}_{0}$ of the electrode is close to $0.01 \mathrm{~cm} \mathrm{~s}^{-1}$. (same condition as that of urine). EIS measurement showed that the $\mathrm{k}_{0}$ value was brought back to $0.012 \mathrm{~cm} \mathrm{~s}^{-1}$ after activation.

In summary, we assessed that this very novel activation process finds very convincing interests for the monitoring of analytes in real samples such as blood, urine etc because of the very short activation times and tunable current density required. However, in real samples adsorbents could accumulate on the surface of the electrode which can be desorbed by applying stronger negative pulses (indicated by increase in $\mathrm{k}_{0}$ value after activation).

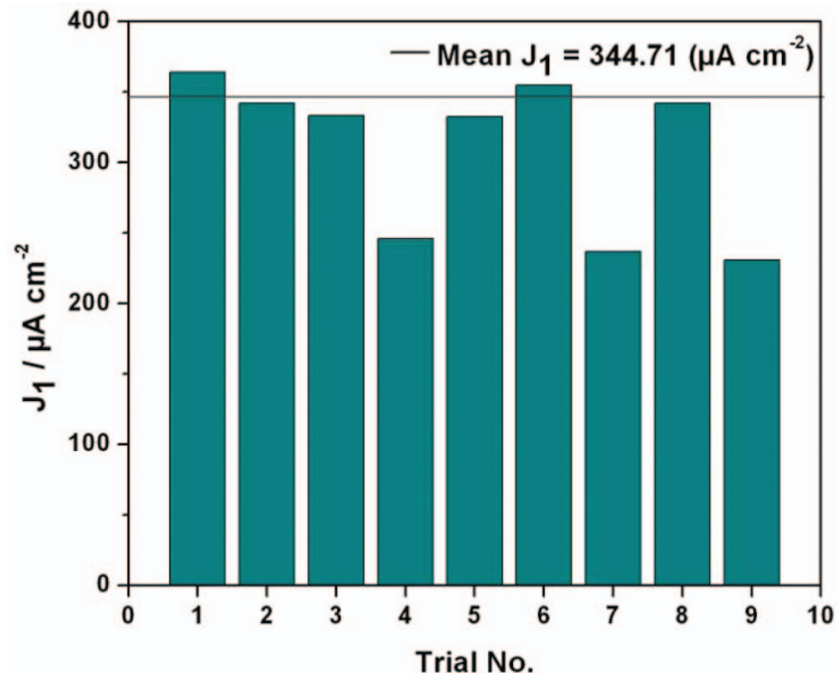

Figure 9. Current density $\mathrm{J} 1\left(\mu \mathrm{A} \mathrm{cm}{ }^{-2}\right)$ of the peak P1 measured from $\mathrm{CV}$ in urine versus trial number. The peak values $\mathrm{J} 1$ of activated trails are close to $350 \mu \mathrm{A} \mathrm{cm}^{-2}$ and if the electrodes are not activated (trial no: 4, 7 and 9) this value is dropped by $25 \%$. 


\section{Conclusions}

It has been demonstrated that this electrochemical treatment retrieve the lost reactivity of BDD electrodes when aged in air as well as in solutions or fouled by a medium. The higher the current density, the lower the time require to activate, and better the result. By tuning the above mentioned parameters (current density, pulse duration and number of pulses, and type of the electrolyte, etc.), one can increase the charge transfer rate constant $\mathrm{k}_{0}$ to reach values above $0.01 \mathrm{~cm}$ $\mathrm{s}^{-1}$. The other advantage of this technique is to enhance the reusability of the BDD electrode. As opposed to other more conventional pre-treatments techniques reported in the literature, such as anodic, cathodic or thermal ones, this novel electrochemical pre-treatment is relatively simpler, fast, and requires a minimum of resources.

Also, the real breakthrough is that it can be successfully performed directly in the measuring solution especially in a biofluid. As a result this electrochemical activation can be performed prior to analytical measurements to ensure reliable and reproducible results, especially when the electrode has not been used for a long period of time. It also opens up the door to long term field measurements where electrodes are prone to fouling when immersed for long periods of time in liquids, including on-line measurement since electrodes may be regenerated very quickly in-situ within biological medium (uric acid quantification with in-situ cleaning in human urine will be published soon).

\section{Acknowledgment}

The authors thank veterinary hospital Maison Alfort, France for supplying bovine blood as well as the Burgundy wine Domaine Philippe Colin, in Chassagne Montrachet, France for their welcome and provision of red wine test samples.

\section{References}

1. M. Panizza and G. Cerisola, Electrochim Acta, 51, 191 (2005).

2. R. Ramesham and M. F. Rose, Diam. Relat. Mater, 6, 17 (1997).

3. G. M. Swain, J. Electrochem. Soc., 141, 3382 (1994).

4. G. M. Swain and R. Ramesham, Anal. Chem., 65, 345 (1993)

5. M. C. Granger, M. Witek, J. Xu, J. Wang, M. Hupert, A. Hanks, M. D. Koppang, J. E. Butler, G. Lucazeau, M. Mermoux, J. W. Strojek, and G. M. Swain, Anal. Chem. 72, 3793 (2000).

6. C. E. Nebel, D. Shin, B. Rezek, N. Tokuda, H. Uetsuka, and H. Watanabe, J. R. Soc. Interface, 22, 439 (2007).
7. J. Iniesta, P. A. Michaud, M. Panizza, and C. Comninellis, Electrochem. Comm., 3 , 346 (2001).

8. F. Montilla, P. A. Michaud, E. Morallón, J. L. Vázquez, and C. Comninellis, Electrochim Acta, 47, 3509 (2002).

9. J. Iniesta, P. A. Michaud, M. Panizza, G. Cerisola, A. Aldaz, and C. Comninellis, Electrochim Acta, 46, 3573 (2001).

10. W. Yantasee, B. Charnhattakorn, G. E. Fryxell, Y. Lin, C. Timchalk, and R. S. Addleman, Anal. Chim. Acta, 620, 55 (2008).

11. J. Wang and L. D. Hutchins, Anal. Chem., 571536 (1985).

12. B. F. Y. Yon Hin and C. R. Lowe, Anal. Chem., 59, 2111 (1987).

13. J. Davis and R. G. Compton, Anal. Chim. Acta, 404, 241 (2000).

14. B. Hoyer and T. M. Florence, Anal. Chem., 59, 2839 (1987).

15. E. Vanhove, J. de Sanoit, J. C. Arnault, S. Saada, C. Mer, P. Mailley, P. Bergonzo, and M. Nesladek, Phys. stat. sol., 204, 2931 (2007).

16. C. H. Goeting, F. Marken, A. Gutierrez-Sosa, R. G. Compton, and J. S. Foord, Diam Relat. Mater, 9, 390 (2000).

17. G. R. Salazar-Banda, L. S. Andrade, P. A. P. Nascente, P. S. Pizani, R. C. Rocha-Filho, and L. A. Avaca, Electrochim Acta, 51, 4612 (2006).

18. N. Wisniewski and M. Reichert, Coll. Surf. B (Biointerfaces), 18, 197 (2000).

19. A. Kraft, Int. J. Electrochem. Sci., 2, 355 (2007).

20. T. N. Rao, D. A. Tryk, K. Hashimoto, and A. Fujishima, J. Electrochem. Soc., 146, 680 (1999).

21. F. Beck, W. Kaiser, and H. Krohn, Electrochim Acta, 45, 4691 (2000).

22. K. B. Holt, C. Forryan, R. G. Compton, J. S. Foord, and F. Marken, New J. Chem., 27, 698 (2003).

23. E. Vanhove, J. de Sanoit, P. Mailley, M-A Pinault, F Jomard, and P. Bergonzo, Phys. stat. sol., 206, 2063 (2009).

24. P. Canizares, J. Garcia-Gomez, J. Lobato, and M. A. Rodrigo, Ind. Eng. Chem. Res., 42, 956 (2003).

25. E. Popa, Y. Kubota, D. A. Tryk, and A. Fujishima, Anal. Chem., 72, 1724 (2000).

26. A. Salimi, H. MamKhezri, and R. Hallaj, J. Talanta., 70, 823 (2006).

27. B. V. Sarada, Tata N. Rao, D. A. Tryk, and A. Fujishima, Anal. Chem., 72, 1632 (2000).

28. R. Kiran, J. de Sanoit, and E. Scorsone, Patent application no: 1151341 (2011).

29. M. P. Seah, Surf. Interface Anal., 20, 243 (1993).

30. M. A. Rodrigo, P. A. Michaud, I. Duo, M. Panizza, G. Cerisola, and Ch. Comninellis, J. Electrochem. Soc., 148, D60 (2001).

31. T. N. Rao, B. H. Loo, B. V. Sarada, C. Terashima, and A. Fujishima, Anal. Chem., 74, 1578 (2002).

32. C. Terashima, T N. Rao, B. V. Sarada, D. A. Tryk, and A. Fujishima, Anal. Chem., 74, 895 (2002).

33. N. G. Anderson, N. L. Anderson, and S. L. Tollaksen, Clin. Chem., 25, 1199 (1979).

34. H. B. Suffredini, V. A. Pedrosa, L. Codognoto, S. A. S. Machado, R. C. Rocha-Filho, and L. A. Avaca, Electrochim Acta, 49, 4021 (2004).

35. E. Mahé, D. Devilliers, and Ch. Comninellis, Electrochim Acta, 50, 2263 (2005).

36. R. Hoffmann, A. Kriele, H. Obloh, J. Hees, M. Wolfer, W. Smirnov, N. Yang, and C. E. Nebel, Appl. Phys. Lett., 97, 052103 (2010).

37. B. Marselli, J. Garcia-Gomez, P.-A. Michaud, M. A. Rodrigo, and Ch. Comninellis, J. Electrochem. Soc., 150, D79 (2003).

38. R. Kiran, L. Rousseau, G. Lissorgues, E. Scorsone, A. Bongrain, B. Yvert, S. Picaud, P. Mailley, and P. Bergonzo, Sensors, 12, 7669 (2012). 